\title{
CORRIGENDUM
}

\section{The importance of bioavailability of dietary iron in relation to the expected effect from iron fortification}

M Hoppe, L Hulthén and L Hallberg

European Journal of Clinical Nutrition (2013) 67, 1226; doi:10.1038/ejcn.2013.191

Correction to: European Journal of Clinical Nutrition (2008) 62, 761-769; doi:10.1038/sj.ejcn.1602776; published online 30 May 2007

Since the publication of this paper, the authors have noticed that there are missing brackets at the end of the equation on page 763 .
The correct equation should read as follows:

$$
t=\left(M_{0}-M_{\mathrm{t}}\right) / L-\left(1 / L k_{2}\right) \ln \left(\left(k_{1} e^{-k_{2} M_{0}}-L\right) /\left(k_{1} e^{-k_{2} M_{\mathrm{t}}}-L\right)\right)
$$

The authors apologize for any inconvenience caused. 